Original Article

\title{
DRUG UTILIZATION PATTERN STUDY IN YOUNG ADULT PATIENTS OF CUTANEOUS ADVERSE DRUG REACTIONS
}

\section{NAGARATNAM ${ }^{1}$, B. DEEPIKA ${ }^{2}$, C. DEEPALATHA ${ }^{3}$}

${ }^{1}$ Department of Pharmacology, Santhiram Medical College and General Hospital, Nandyal, ${ }^{2}$ Department of Pharmacology, Prathima Medical College, Karimnagar, ${ }^{3}$ Patient Safety Pharmaco Vigilance Technical Associate, Bhaskar General Hospital

Email: cdeepalatha@gmail.com

Received: 11 Jul 2018, Revised and Accepted: 07 Sep 2018

\section{ABSTRACT}

Objective: To evaluate prevalence of cutaneous adverse reactions in young adult age group using ADR notification form. To create awareness in hospitals and health sectors, to establish drug safety monitoring units for mother and child care.

Methods: Individual case safety reports of 46 patients from various hospitals were analyzed using CDSCO forms. To tabulate data on drugs, doses, systems, ADRs and factors for causation of cutaneous ADRs.

Results: Females are more prone compared to males due to pregnancy at young age with increased use of Iron combinations, antibiotics and antiepileptic's in young adult age groups (20-30yrs) among cutaneous ADRs.

Conclusion: We conclude the need for establishment of drug safety units with generic units for maternity sections and use of drugs in pre and post natal period, as pregnancy and adult age are risk factors for cutaneous adverse drug reactions. Every hospital structure needs special caution on drug lots of iron preparations, antibiotics, analgesics, antiepileptic's to be used in Obstetrics and Gynecology departments.

Keywords: Cutaneous ADRs, Antibiotics, Iron preparations, Drug safety units

(c) 2018 The Authors. Published by Innovare Academic Sciences Pvt Ltd. This is an open access article under the CC BY license (http://creativecommons.org/licenses/by/4.0/) DOI: http://dx.doi.org/10.22159/ijcpr.2018v10i6.30965

\section{INTRODUCTION}

Cutaneous ADRs are predominant with Non-Steroidal Antiinflammatory drugs, Anti-epileptics and Antimicrobials [1]. Known causative factors include hypersensitivity, polypharmacy and decreases of generic brands [2]. The present study is to create awareness among health care professionals to promote generic drugs and responsible use of drugs towards vulnerable patient'swith age group of 20-30 where in pregnancy is very common.

\section{MATERIALS AND METHODS}

The present study is carried out taking cutaneous ADRs from various hospitals across Telangana and Andhra Pradesh states. Collection of Individual case safety report forms along analysis of causative factors like, age, gender, drugs, doseregimen and studywas carried out for 3 mo on 46 patients of cutaneous Adverse Drug Reactions. Causality assessment done, using WHO-UMC scale and severity assessment done using Hartwig Seigel scale. Dataanalysed and results tabulated.

\section{RESULTS}

Total patients of 46 were include in the study of which $27(58.69 \%)$ females and $19(41.30 \%)$ males. The present study shows that Ferric Carboxy Maltose, parental iron preparation and antibiotics like Cephalosporins (ceftriaxone) and Tinidazole used for pregnancy induced anemia. Antibiotics used for pre and post-operative sections and anti-epileptics (Phenytoin) are the main drugs that contribute to increase incidence of cutaneous ADRs in group 20-30 y [3].

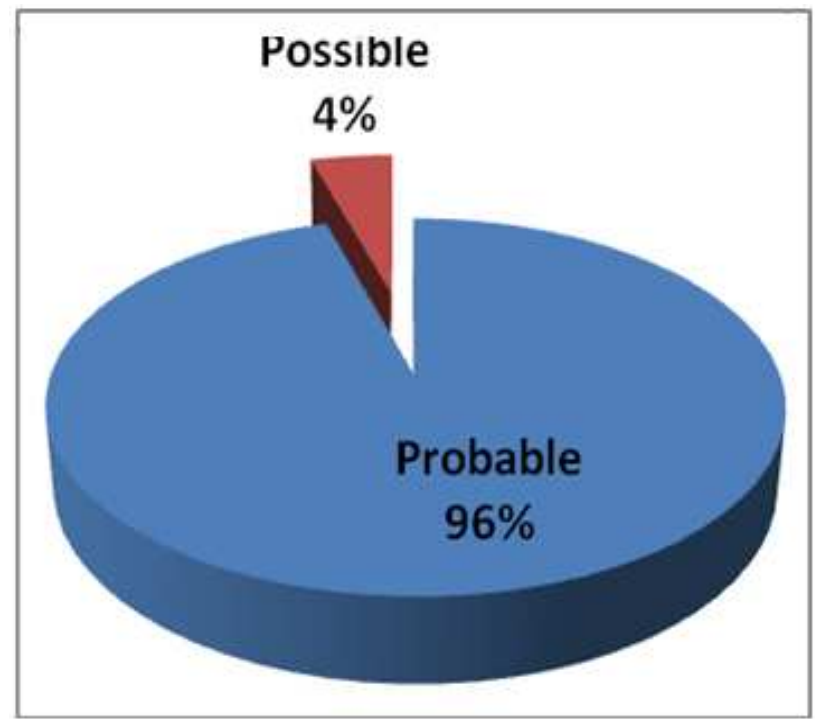

Fig. 1: Percentage distribution of causality assessment

Table 1: Gender wise distribution of patients

\begin{tabular}{lll}
\hline Gender & No. of Patients & Percentage (\%) \\
\hline Females & 27 & 58.69 \\
Males & 19 & 41.30 \\
\hline
\end{tabular}


Table 2: Distribution of types of drugs responsible for ADRs

\begin{tabular}{lll}
\hline Drugs & No. of patients & Percentage \\
\hline Iron carboxy maltose(3)+Iron sucrose(6) & 9 & 20 \\
Antibiotcs & 25 & 55 \\
NSAIDs & 2 & 4.4 \\
Antiemetics & 2 & 4.4 \\
Multivitamins & 4 & 9 \\
Antiepileptics & 3 & 7 \\
Immunosuppressants & 1 & 2 \\
\hline
\end{tabular}

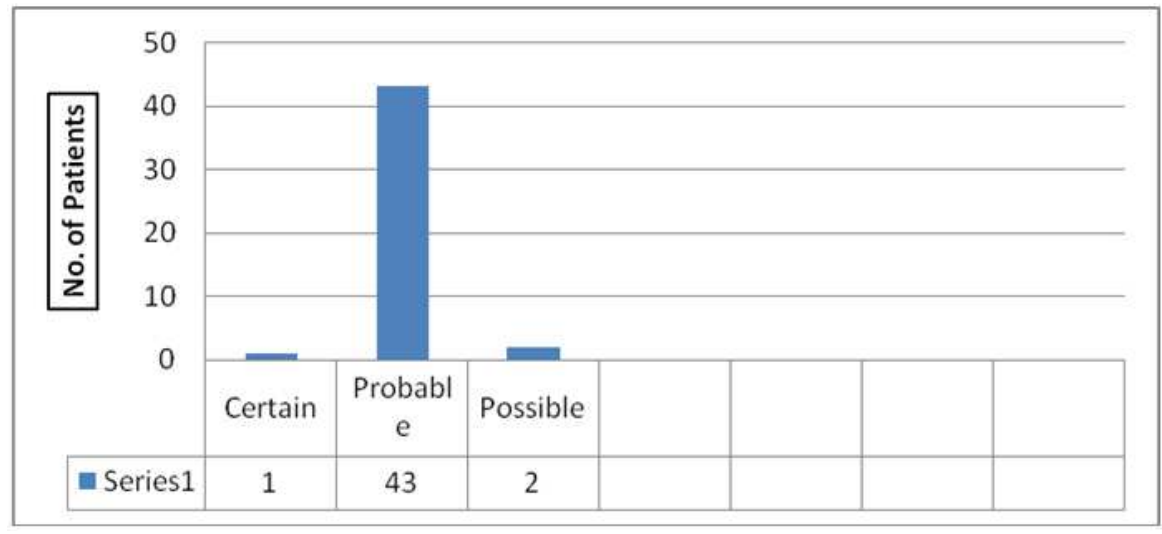

Fig. 2: Distribution of causality assessment of ADRs

Table 3: Usage of brand drug vs generic drugs

\begin{tabular}{lll}
\hline Drugs & No. of patients & Percentage (\%) \\
\hline Brand & 29 & 62 \\
Generic & 8 & 17 \\
\hline
\end{tabular}

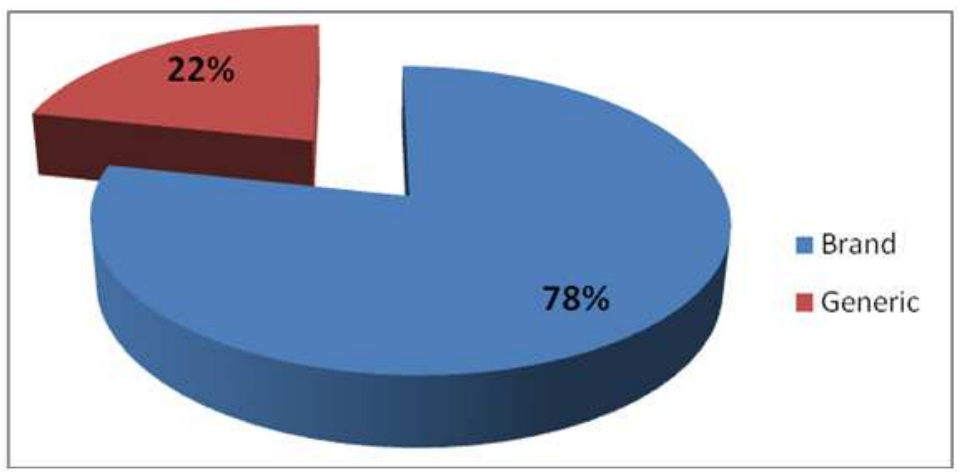

Fig. 3: Usage of brand drug vs generic drugs

Table 4: Causality assessment distribution among patients

\begin{tabular}{lll}
\hline Causality assessment & No. of Patients & Percentage (\%) \\
\hline Certain & 01 & 2.17 \\
Probable & 43 & 93.4 \\
Possible & 02 & 4.34 \\
\hline
\end{tabular}

Table 5: Drugs associated with systems involved in ADRs

\begin{tabular}{lll}
\hline Drugs & Systems involved in ADRs & Percentage (\%) \\
\hline Iron carboxy maltose+Iron sucrose & Cutaneous & 20 \\
Antibiotcs () & Cutaneous+GIT & 55 \\
NSAIDs & Cutaneous & 4.4 \\
Antiemetics & Cutaneous & 4.4 \\
Multivitamins & Cutaneous & 9 \\
Antiepileptics & Cutaneous & 7 \\
Immunosuppressants & Extra pyramidal Symptoms & 2 \\
\hline
\end{tabular}




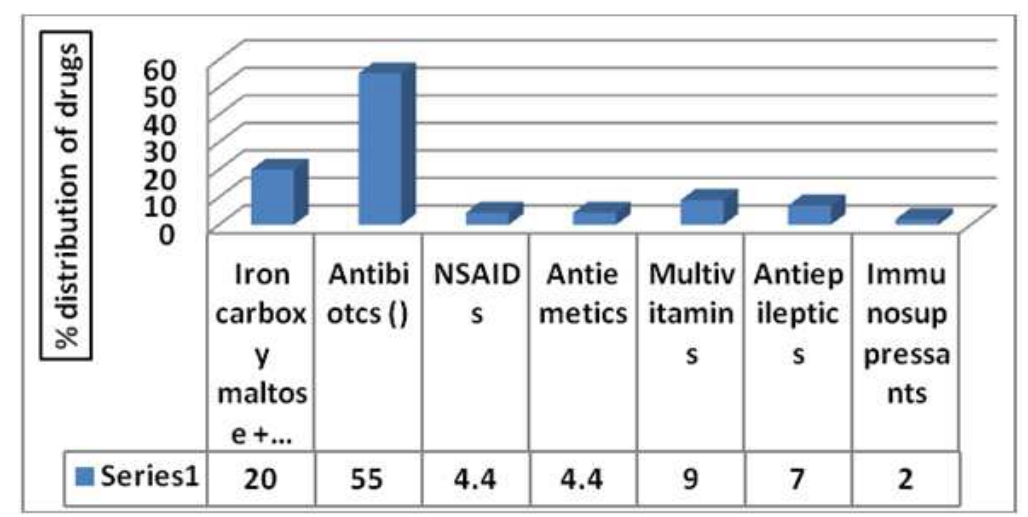

Fig. 4: Drug associated with systems involved in ASRs

\section{DISCUSSION}

This study shows $20 \%$ of patients suffer due to administration of parental iron preparation during pregnancy and 36\% of patients suffer due to antibiotics used in prenatal and postnatal periods suggesting $56 \%$ of patients young adult age are females who have attained pregnancy indicating the need of art to establish maternal section in pharmacy section of hospitals wherein closed monitoring of drugs is needed, establishment of P drug concept by Obstetrics and Gynecology department and supply of generic drugs is maintained to restrict cutaneous ADRs [4]. Other drugs which cause cutaneous ADRs include antibiotics used for diarrheal infections, tuberculosis, leprosy, pharyngitis suggesting improvement of hygienic conditions and use of prescribed drugs and to curb over the counter drugs. Use of NSAIDs, antiemetics, antiepileptics is minimal. The percentage of cutaneous ADRs caused by branded drugs $(63 \%)$ is more compared to generic (17\%) drugs [5]. Hence generic pharmacies are recommended to decrease the occurrence of cutaneous ADRs.

\section{CONCLUSION}

We conclude that cutaneous ADRs are more predominant in females than males as drugs used in pregnancy safe and are responsible for cutaneous ADRs hence need of the hour is to maintain separate section for drugs used in pregnancy with generic drugs in every hospital and caution to be taken for drug lots causing cutaneous ADRs [6]. Rise of every clinician to develop "P" drug concept in order to use drugs in pregnant women.

\section{AUTHORS CONTRIBUTIONS}

All the author have contributed equally

\section{CONFLICT OF INTERESTS}

Declared none

\section{REFERENCES}

1. Chatterjee S, Ghosh AP, Barbhuiya J, Dey S. Adverse cutaneous drug reactions: A one year survey at a dermatology outpatient clinic of a tertiary care hospital. Indian J Pharmacol 2006;38:429-31.

2. Moore N, Lecointre D, Noblet C, Mabile M. Frequency and cost of serious adverse drug reactions in a department of general medicine. BR J Clin Pharmacol 1998;45:301-8.

3. Roujeau JC, Stern RS. Severe adverse cutaneous reactions to drugs. N Engl J Med 1994;331:1272-85.

4. Bilimoria FE, Shah BE. Drug reactions. In: Valia RG, Valia RR. IAVDL textbook of dermatology.3rd edition. India Blalani Publication; 2008. p. 1633-68.

5. World Health Organisation. Collaborating centre for International Drug Monitoring. Geneva: World Health Organization. WHO publication DEM/NC/8; 1984.

6. Pir Mohamed M, Breckenridge AM, Kitteringham NR, Park BK. Adverse drug reactions. Br Med J 1998;316:1295-8.

7. Deepa Latha Ciddhavaduta, Samee Knuta, Deepika Baloju. Analysis of cutaneous adverse drug reactions on using commonly prescribed drugs at a tertiary care hospital. J Evidence Based Med 2018;5:2349-2570.

8. Nayak S, Acharya B. Adverse cutaneous drug reaction. Indian J Dermatol 2008;53:2-8.

9. Breathnach SM, Hinter H. Adverse drug reactions and the skin. Oxford: Blackwell Scientific; 1992.

10. Sharma VK, Sethuraman G. Adverse cutaneous reactions to drugs: an overview. J Postgrad Med 1996;4:15-22. 